\title{
Sensory Integration Training Tool Design for Children with Autism Spectrum Disorder
}

\author{
Lijun Jiang ${ }^{1 \mathrm{a}}$, Maoteng $\mathrm{Ye}^{1 \mathrm{~b}}$ and Zhelin $\mathrm{Li}^{1}$ \\ ${ }^{1}$ South China University of Technology, Higher Education Mega Center, Panyu District, Guangzhou City, Guangdong \\ Province, China
}

\begin{abstract}
This study aims to design a training tool for therapy of children with autism spectrum disorder (ASDs). Typically, ASDs pass through obstacle track several times with sandbags, which should be picked up from starting point and threw into a box at the end during sensory integration therapy. Counting the sandbags can help ASDs to have concept about the progress of mission. We redesign the counting box named "Skybox" which can help counting by playing sound after detect something throw in it. Aims to probe into the sound preference of two main subjects, an experiment with four kinds of sounds is conducted in this paper by using the method of paired comparisons. The result shows they like animals most, followed by human voice and nature sounds, and music instrument is the last. The material preference experiment shows two subjects like acrylic most, wood and paper are secondary while furry is the last. Skybox shortens their training time for $23.53 \%, 29.87 \%$ and $37.37 \%$ in three different projects. We consider that Skybox attracts ASDs therefore reduces their distraction and improves their performance in the usability test.
\end{abstract}

\section{Introduction}

Autism spectrum disorders (ASD) are a group of neurodevelopmental disorders characterized by impairments in social interaction and communication, as well as repetitive behaviors and restricted interests.[1,2] There are about 35 million ASDs in the world, 1.5 million of them are in China.[3] Part of them can blend into society after early and long-term therapy.

Sensory integration therapy is one of the effective therapy.[4] Typically, one sensory integration therapy (one class) includes serval projects. Many projects have a track with obstacles. ASDs need to climb over obstacles, which set by the therapist, again and again. ASDs are required to pass through the same track 4 to 8 rounds (with sandbags or something else to counting) depending on their capability. The therapy seems boring to ASDs.

Therefore, we aim to design fun training tool to increase ASDs' interest of sensory integration training, and then enhance their training effects. Counting box was chose to improve for its universality, ordinary and high relation to the track.

\footnotetext{
a 1jjiang@scut.edu.cn

b xiaomieye@163.com
} 


\section{Training tool design}

There aren't any autistic toys could be make as reference for autism sensory integration therapy. Whereas, a case in "Fun Theory Award" is similar. [5] When people throwing rubbish into the bin, it plays the sound of something falling down, that motivates them to collect more rubbish. Our design uses it for reference and make a usefully prototype finally.

Boys R (4-year-old) and Z (8-year-old) diagnosed with ASD are our main subjects. Boy Y, who diagnosed with low severity level of ASD, doesn't have sensory integration class. G is a typical developing (TD) girl who has an autistic brother.

\subsection{Step 1: Product Concept}

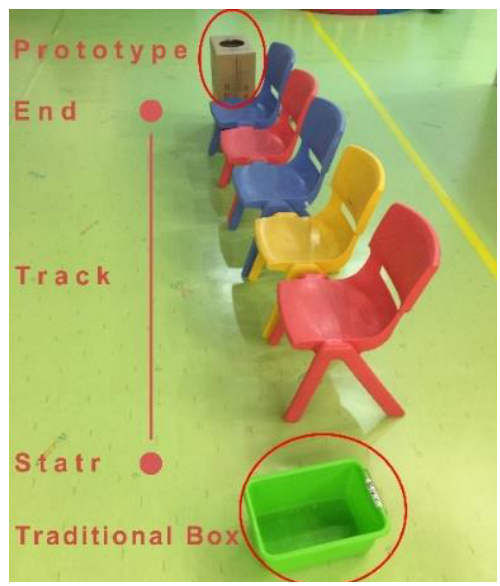

Figure 1. Schematic diagram of product concept evaluation

To ensure fun theory [5] works for ASDs, we conduct a product concept evaluation with a paper prototype (Figure 1, end of the track). It consists of paper body and electronic part that can make the sound of falling to the chasm when it detects something passing through the hold. $\mathrm{R}$ and $\mathrm{Z}$ show interest to the prototype. However, $\mathrm{R}$ is afraid of the sound. $\mathrm{Y}$ is curious about the box and departs it without talking or paying any attention to experimenters. G ask me how the box works.

Compare with normally developing children, autistic children have different listening preferences in regard to speech.[6]. We haven't find study about ASDs' sound preference, and assume ASDs have different sound preference from TD due to their imbalanced brain functions. Therefore, a sound preference experiment is needed.

\subsection{Step 2: Sound Preference Experiment}

Eight sounds are chose to be the experiment materials. Dog, cat, drop, wave, great, cheer, single-tone of piano, portamento of piano. They can be divided into four kinds of types: animals (dog, cat), natural (drop, wave), human voice (great, cheer) and musical instrument (single-tone of piano, portamento of piano). It also can be divided into two kinds of length: single tone sound (dog, drop, great, and single-tone of piano) and persistent sound (cat, wave, cheer, and portamento of piano). The experiment also sets eight sounds which have the similar volume and various persist time.

To rank the sounds strictly and eliminate the effect of hand-preference (right-hander or left-hander), paired comparison method is used in this experiment. Experiment is divided into two groups, each group has 28 pairs of sounds that can generates 28 choices. Two subjects $(Z$ and $R)$ participate in experiment. The sequence shows in table 1 . 
Table 1. Sounds appear sequence

\begin{tabular}{llllllllll}
\hline Sequence Sound & Dog & Cat & Drop & Wave & Great & Cheer & $\begin{array}{l}\text { Single } \\
\text {-tone }\end{array}$ & $\begin{array}{l}\text { Porta- } \\
\text { mento }\end{array}$ \\
\hline Sound & & & B28 & B27 & B15 & B14 & B6 & B5 & B1 \\
Dog & A1 & - & B26 & B25 & B13 & B12 & B4 & B3 \\
Drop & A2 & A3 & - & B24 & B23 & B11 & B10 & B2 \\
Wave & A14 & A4 & A5 & - & B22 & B21 & B9 & B8 \\
Great & A15 & A16 & A6 & A7 & - & B20 & B19 & B7 \\
Cheer & A23 & A17 & A18 & A8 & A9 & - & B18 & B17 \\
Single-tone of piano & A24 & A25 & A19 & A20 & A10 & A11 & - & B16 \\
Portamento of piano & A28 & A26 & A27 & A21 & A22 & A12 & A13 & - \\
\hline
\end{tabular}

The experiment conduct in an independent quiet room. One subject participants with one experimenter and one therapist at one time. Two boxes placed on the table. Each box has a button. The box can play a sound once the button is pushed. At the beginning of each test, experimenter pushes two buttons to show which button corresponding to which sound. Then the subject has time to play two boxes by pushing two buttons freely. After subject is familiar with the sounds, therapist asks him which sound he likes. Subject pushes the button to answer. Then experimenter records the data. We adapt this method because ASDs have deficit in speaking. The result shows in table 2.

Table 2. Experience result of sound preference

\begin{tabular}{|c|c|c|c|c|c|c|c|c|}
\hline \multirow{2}{*}{$\begin{array}{l}\text { Item } \\
\text { Sound }\end{array}$} & \multicolumn{2}{|c|}{ Animals } & \multicolumn{2}{|c|}{ Natural } & \multicolumn{2}{|c|}{ Human voice } & \multicolumn{2}{|c|}{ Music instrument } \\
\hline & Dog & Cat & Drop & Wave & Great & Cheer & Single-tone & Portamento \\
\hline Chose & 14 & 21 & 8 & 19 & 8 & 20 & 8 & 14 \\
\hline Chose & \multicolumn{2}{|c|}{35} & \multicolumn{2}{|c|}{27} & \multicolumn{2}{|c|}{28} & \multicolumn{2}{|c|}{22} \\
\hline
\end{tabular}

Animals' sounds are the most popular, followed by human voice and natural. Music instrument performs the worst. This outcome meets Anke Prothmann's research in a sense, that their study shows ASDs prefers to interact with dogs rather than people or objects.[7]

Besides, the result shows they prefer persistent sounds (74 times) rather to single tone sounds (39 times). We consider the quantity of stimulus makes this different.

\subsection{Step 3: Material Preference Experiment}

This experiment, by using the method of paired comparisons, aims to probe into the material preference of two subjects. Four common materials are chose in the experiment, include paper, wood, acrylic and plush. To eliminate the color different, we painted the acrylic brown and chose the brown plush which approach to the color of paper and wood looked. The experiment uses four boxes, which have the same size and the same function that play the same sound when detect something drop into the boxes.

The experiment conducts in the real training circumstance. Experimenters place two boxes, which appeared in a random order like step 2, at the end of the track. Subjects throw the sandbags, which they bring from the beginning of the track, into the box they like. After that, experimenters record the data and change the boxes for next throw. The result shows that acrylic is the most popular, followed by wood and paper. Plush is the less.

ASDs show great interest to the interior of the boxes. Acrylic box was sprayed paint, but partly keeps its transmission of light. Paper box and wood box have similar brightness of the interior as well as similar texture because paper is made from wood. Plush box performs worse. ASDs seems scare for 
a plush box with a dark hole which can make sound after eating a sandbag. It's hard to draw conclusion whether the material or the inner brightness of boxes effect the result. Nonetheless, we choose acrylic for its attractive to ASDs.

\subsection{Step 4: Prototype}

Generally, the autistic children surveyed prefer cool color to warm color; they prefer green, followed by blue, red, purple, orange and yellow.[8] Considering the floor is green, we use sky blue acrylic to compose the body of the prototype. We name it "Skybox" since its color and ASDs also called "children from stars". (Figure 2, 3)

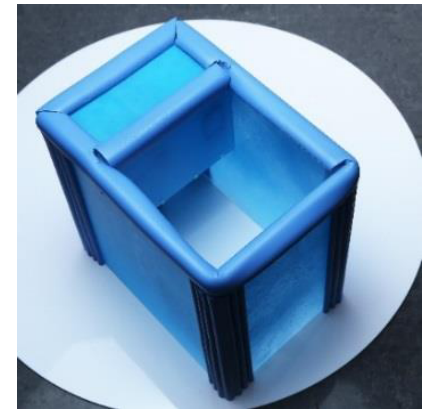

Figure 2. Skybox outside

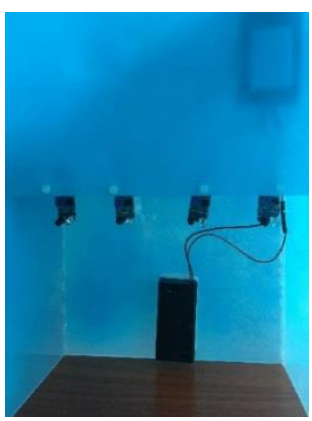

Figure 3. Skybox inside

The electronic part of Skybox consists of Arduino, battery pack, transformer, loudspeaker and four IR evading obstacle sensors. All of them are out of children's sight. Battery pack is placed to the bottom of Skybox, so that users can replace batteries conveniently.

Skybox is $30 \mathrm{~cm}$ height. ASDs can throw the sandbags (or anything else for counting) into Skybox easily whatever they are sitting on the floor, standing on the floor even standing on the chair. The rubber strip which cover the edge of Skybox can make it safe to ASDs. The bottom was remove since we found that it doesn't need to store sandbags but needs to take out them conveniently. ASDs can hear the sound but can't see anything from the opening to the bottom of Skybox. That make it seems dramatic and attractive.

\subsection{Step 5: Evaluation}

Table 3. Skybox experiment outcome

\begin{tabular}{|c|c|c|c|c|c|c|}
\hline \multirow{3}{*}{$\begin{array}{l}\text { Subject } \\
\text { Mission } \\
\text { Mode }\end{array}$} & \multicolumn{4}{|c|}{$\mathrm{R}$} & \multirow{2}{*}{\multicolumn{2}{|c|}{$\begin{array}{c}\text { Z } \\
\text { Kangaroo Jump }\end{array}$}} \\
\hline & \multicolumn{2}{|c|}{ Climbing } & \multicolumn{2}{|c|}{ Monkey Creep } & & \\
\hline & Tradition & Skybo & Tradition & Skybox & Tradition & After \\
\hline $1^{\text {st }}$ & $1^{\prime} 30^{\prime \prime}$ & $57^{\prime \prime}$ & $49^{\prime \prime}$ & $16^{\prime \prime}$ & $15^{\prime \prime}$ & $14^{\prime \prime}$ \\
\hline $2^{\text {nd }}$ & $1^{\prime} 05^{\prime \prime}$ & $15^{\prime \prime}$ & $15^{\prime \prime}$ & $15^{\prime \prime}$ & $12^{\prime \prime}$ & $15^{\prime \prime}$ \\
\hline $3^{\text {rd }}$ & 1'17" & $1^{\prime} 11^{\prime \prime}$ & $15^{\prime \prime}$ & $22^{\prime \prime}$ & $17^{\prime \prime}$ & $15^{\prime \prime}$ \\
\hline $4^{\text {th }}$ & $1^{\prime} 28^{\prime \prime}$ & $48^{\prime \prime}$ & $58^{\prime \prime}$ & $34 "$ & $33^{\prime \prime}$ & $10^{\prime \prime}$ \\
\hline $5^{\text {th }}$ & $52^{\prime \prime}$ & $34^{\prime \prime}$ & $16^{\prime \prime}$ & $30^{\prime \prime}$ & & \\
\hline $6^{\text {th }}$ & $33^{\prime \prime}$ & $27^{\prime \prime}$ & & & & \\
\hline $7^{\text {th }}$ & $27^{\prime \prime}$ & $23^{\prime \prime}$ & & & & \\
\hline $8^{\text {th }}$ & $47^{\prime \prime}$ & $25^{\prime \prime}$ & & & & \\
\hline Summation & $479^{\prime \prime}$ & $300^{\prime \prime}$ & $153^{\prime \prime}$ & $117^{\prime \prime}$ & $77^{\prime \prime}$ & $54^{\prime \prime}$ \\
\hline Average & $59.875^{\prime \prime}$ & $37.5^{\prime \prime}$ & $30.6^{\prime \prime}$ & $23.4^{\prime \prime}$ & $19.25^{\prime \prime}$ & $13.5^{\prime \prime}$ \\
\hline Shorten & \multicolumn{2}{|c|}{$37.37 \%$} & \multicolumn{2}{|c|}{$23.53 \%$} & \multicolumn{2}{|c|}{$29.87 \%$} \\
\hline
\end{tabular}


Usability test conducted in the daily training circumstance instead of special circumstance. It is vital to select appropriate training project to evaluate Skybox. "Squat on cushion" is a training project of R, who can't squat for a long time due to the weakness of relevant muscle. $\mathrm{R}$ has to finish serval rounds in this project. In each round, therapist count to ten seconds when $\mathrm{R}$ keep squatting on cushion. Sometime, when R performs well, therapist may slow down the counting speed stealthily. Therefore, the relationship between consumption of time and the effect of Skybox is blurry in "squat on cushion". We exclude this kind of project and select three projects which have clear relationship between consumption of time and training performance (Table 3 ).

In the first day, we recorded the consumption of time during each project. The next day, we replace the traditional counting box with Skybox. Each project measure at the same periods of time on two day. The length of the track and the therapist were the same, too. The result showed in table 3.

\section{Discussion}

The result amazes us since we assume about $10 \%$ descend before evaluation. This paper think Skybox works by reduce ASDs' distraction. An early feature of autism spectrum disorder is impaired joint attention as manifested by a lack of pointing, showing, or bringing objects to share interest with others, or failure to follow someone's pointing or eye gaze.[2] When ASDs loses the attention to the project, time consumption rises in abundance.

Skybox may provide an interesting point to ASDs and reduces their distraction. That makes the score looks significant. Actually, there is no significant different between two mode when ASDs don't distract. It should be noted that Skybox's evaluation conducted only in two days, the skybox is still fresh to two subjects. The attraction of Skybox to ASDs may drop after a period. Anyway, it improves the training result. Furthermore, reduce of distraction has important meaning for therapy.

\section{General discussion}

The long-term significance of this study aims to help ASDs blend into commend society. ASDs aren't capable enough to use universal smart products like ordinary people does. There are less smart products designed for ASDs therefore they seldom use smart products. Sometime ASDs contact smart produces "passively" such as watching video on TVs or smart phones. In this study, ASDs use smart product "actively", which we consider it significant.

\section{References}

1. Maenner, M.J., et al. JAMA Psychiatry. 71(3): p. 292-300. (2014)

2. Association, A.P., Diagnostic and Statistical Manual of Mental Disorders, Fifth Edition. (2013)

3. C Shunsen, B Xuejun, Z Risheng. Advances in Psychological Science, 01: p. 60-72. (2011)

4. Simpson, R.L. Focus on Autism and Other Developmental Disabilities. 20(3): p. 140-149. (2005)

5. The World's Deepest Bin. (2009)

6. Klin, A. Journal of Autism and Developmental Disorders. 21(1): p. 29-42. (1991)

7. Prothmann, A., C. Ettrich, and S. Prothmann. Anthrozoös. 22(2): p. 161-171. (2009)

8. C Shuqin, F Wen, S Aijun. CJSE. 05: p. 46-52. (2012) 